\title{
EXPRESSION OF METASTASIS ASSOCIATED PROTEIN 1 AS A POSSIBLE PROGNOSTIC INDICATOR IN ORAL SQUAMOUS CELL CARCINOMA
}

Wedad M. Nawar' $B D$ s, Taissir A. Omar ${ }^{2} P h D$, Hamed A. Fouad ${ }^{2} P h D$, Gamal A. Swaify $P h D$

\begin{abstract} metastasis. play an important role in predicting LN metastasis in OSCC patients. KEYWORDS: OSCC, MTA1, PCNA, LN metastasis

1- Resident in Oral Pathology Department, Faculty of Dentistry, Alexandria University.

2- Professor in Oral Pathology Department.

3- Professor in Cranio Maxillofacial and Plastic Surgery
\end{abstract}

INTRODUCTION: Lymph node (LN) metastasis is one of the most important prognostic factors related to survival of oral squamous cell carcinoma (OSCC). Although, metastasis associated protein 1 (MTA1) overexpression is closely correlated with the metastasis of several human cancers, its role in determining lymph node metastases in OSCC patients remains undefined. Proliferating Cell Nuclear Antigen (PCNA) is the most representative proliferating marker; yet there is a controversy as to whether it can be used as a prognostic marker in OSCC. OBJECTIVES: To evaluate the immunoexpression of MTA1 and PCNA in metastatic versus non-metastatic OSCC; and correlate it with LN

MATERIALS AND METHODS: MTA1 and PCNA immunoexpression was detected immunohistochemically in 20 OSCC specimens; 10 of which had metastatic LNs and 10 with non-metastatic LNs (used as a control group). Their correlation with LN metastasis was evaluated.

RESULTS: MTA1 immunoexpression showed significant correlation with LN metastasis but not with the histologic grade of the tumor. Whereas, PCNA immunoexpression revealed a significant correlation with the histologic grade of the tumor, but not with nodal metastasis. CONCLUSIONS: The present study suggests that MTA1 protein may have a clinical potential to be used as a prognostic factor to identify pathologically node-negative OSCC patients who may be at high risk to develop regional metastasis. On the other hand, PCNA is unlikely to

\section{INTRODUCTION}

The incidence of oral cancer ranks the sixth worldwide (1). Oral Squamous Cell Carcinoma (OSCC) represents approximately $3 \%$ of all malignancies in the body (2) and at least $90 \%$ of all oral malignancies (3). Cancers of the lip and oral cavity accounted for 300,000 cases in 2012 (4) and yet the World Health Organization expects a worldwide rising of OSCC incidence in the next decades (5).

OSCC implies quite significant mortality and morbidity rates (1-3). In spite of the vast amount of research and the advances accomplished in the field of oncology and surgery, the mortality rates remain unchanged $(3,4,6)$, with the 5-year survival rate being as low as 50\% (4).

It is widely accepted that the presence of lymph node metastasis is one of the most important prognostic factors related to survival of OSCC (6). At the time of diagnosis, $75 \%$ of the patients are usually presented with regional metastasis, which reduces the survival rate to $25 \%$; the fact that makes it crucial to establish reliable predictors of occult metastasis in patients with clinically negative lymph nodes (7).

Recent advances in molecular biology have resulted in the discovery of a wide variety of new molecules involved in carcinogenesis; among them is the metastasis associated protein 1 (MTA1) (8). It has been reported that MTA1 overexpression is closely correlated with the invasion and metastasis of several human cancers (9-11). However, only a few studies investigated the role of MTA1 in the prognosis of $\operatorname{OSCC}(12,13)$.

Proliferating Cell Nuclear Antigen (PCNA) is the most representative proliferation marker. The crucial involvement of PCNA in cellular proliferation and its tight association with cancer transformation resulted in the use of
PCNA as a diagnostic and prognostic biological marker in various cancer types (14).

The aim of the present study is to evaluate the expression of MTA1 and PCNA in metastatic versus non-metastatic OSCC, and to correlate its expression with tumor prognosis; in terms of lymph node metastasis.

\section{MATERIALS AND METHODS}

Twenty cases of OSCC, together with their lymph nodes, were collected from the Department of CranioMaxillofacial and Plastic surgery, Faculty of Dentistry, Alexandria University and from private clinics. A written informed consent was taken from all patients. Approval of the Research Ethics Committee, Faculty of Dentistry, Alexandria University, was obtained.

Oral squamous cell carcinoma cases were classified into 2 groups: OSCC cases with nodal metastasis; and OSCC cases without nodal metastasis (used as a control group). Biopsies were taken from all tumor tissues and their resected lymph nodes to be examined in the Department of Oral Pathology, Faculty of Dentistry, Alexandria University.

\section{Histopathologic examination}

Serial sections of 3-4 $\mu \mathrm{m}$ thick were cut from each tissue block, placed on glass slides and stained using hematoxylin and eosin (H \& E) for routine histopathological examination using light microscope.

\section{Immunohistochemical Examination}

Immunohistochemical staining was performed for each section using MTA1 (GeneTex, USA) and PCNA antibodies (Thermo Fisher Scientific, USA) using the labelled streptavidin-biotin (LSAB) complex method (15). 
The sections were then examined by the image analyzer computer system (Leica Qwin 500).

\section{STATISTICAL ANALYSIS}

Analysis of the data was performed using statistical package for scientific studies (SPSS) 17 for Windows. The mean value of the optical density and area percent of MTA1 and PCNA immunoexpression for the 2 groups (Metastatic OSCC and Non-metastatic OSCC) were compared, using student $(\mathrm{t})$ test.

The one-way Analysis of Variance (ANOVA) test was used to compare the mean optical density and mean area percent between the different histologic grades.

The results were expressed in the form of p-values, a pvalue less than 0.05 was considered significant.

\section{RESULTS}

The clinical data of all patients are represented in table 1. The microscopic examination revealed $15 \%$ of the cases to be well differentiated $(n=3), 75 \%$ to be moderately differentiated $(n=15)$ and $10 \%$ poorly differentiated SCC $(n=2)$.

Table 1: Clinical features of the studied OSCC cases.

\begin{tabular}{|c|c|c|c|c|c|c|}
\hline \multirow[t]{2}{*}{ Site } & \multicolumn{2}{|c|}{ Sex } & \multirow{2}{*}{$\begin{array}{c}\text { Age } \\
\begin{array}{c}\text { Min-Max } \\
\text { (mean) }\end{array}\end{array}$} & \multicolumn{2}{|c|}{ LN Metastasis } & \multirow[b]{2}{*}{ Total } \\
\hline & Male & Female & & Positive & Negative & \\
\hline Tongue & 4 & 5 & $\begin{array}{l}44-77 \\
(57.5)\end{array}$ & 7 & 2 & 9 \\
\hline $\begin{array}{l}\text { Alveolar } \\
\text { Ridge }\end{array}$ & 2 & 2 & $\begin{array}{l}54-81 \\
(66.5)\end{array}$ & 1 & 3 & 4 \\
\hline $\begin{array}{l}\text { Retromol } \\
\text { ar Area }\end{array}$ & - & 2 & $\begin{array}{l}55-56 \\
(55.5) \\
\end{array}$ & - & 2 & 2 \\
\hline Palate & - & 1 & 58 & - & 1 & 1 \\
\hline $\begin{array}{l}\text { Lower } \\
\text { Lip }\end{array}$ & 1 & - & 60 & - & 1 & 1 \\
\hline $\begin{array}{l}\text { Submand } \\
\text { ibular }\end{array}$ & 1 & - & 53 & - & 1 & 1 \\
\hline $\begin{array}{l}\text { Buccal } \\
\text { Mucosa }\end{array}$ & 1 & & 48 & 1 & - & 1 \\
\hline $\begin{array}{l}\text { Floor of } \\
\text { the } \\
\text { mouth }\end{array}$ & 1 & - & 72 & 1 & - & 1 \\
\hline Total & $\begin{array}{c}10 \\
(50 \%)\end{array}$ & $10(50 \%)$ & $\begin{array}{c}44-81 \\
(59)\end{array}$ & $\begin{array}{c}10 \\
(50 \%)\end{array}$ & $\begin{array}{c}10 \\
(50 \%)\end{array}$ & $\begin{array}{c}20 \\
(100 \% \\
)\end{array}$ \\
\hline
\end{tabular}

\section{MTA1 immunoexpression}

MTA1 protein was expressed at variable levels and predominantly stained the cytoplasm of tumor cells; nonetheless nuclear reaction was also detected (Figures 13).

No statistical significance was found between MTA1 protein expression and the degree of histologic differentiation of OSCC. On the contrary, a significant correlation was revealed between MTA1 overexpression and lymph node metastasis, in terms of optical density, but not in terms of area percentage.

\section{PCNA Immunoexpression}

PCNA was expressed at variable levels and stained the nuclei of epithelial cells, especially confined to the basal and suprabasal cells. However, a faint cytoplasmic reaction was observed (Figures 4-6).

The difference in the mean optical density and area percentage showed statistical significance $(\mathrm{p} \leq 0.05)$ between the well, moderately and poorly-differentiated groups. Nevertheless, it was insignificant between the metastatic and non-metastatic groups.

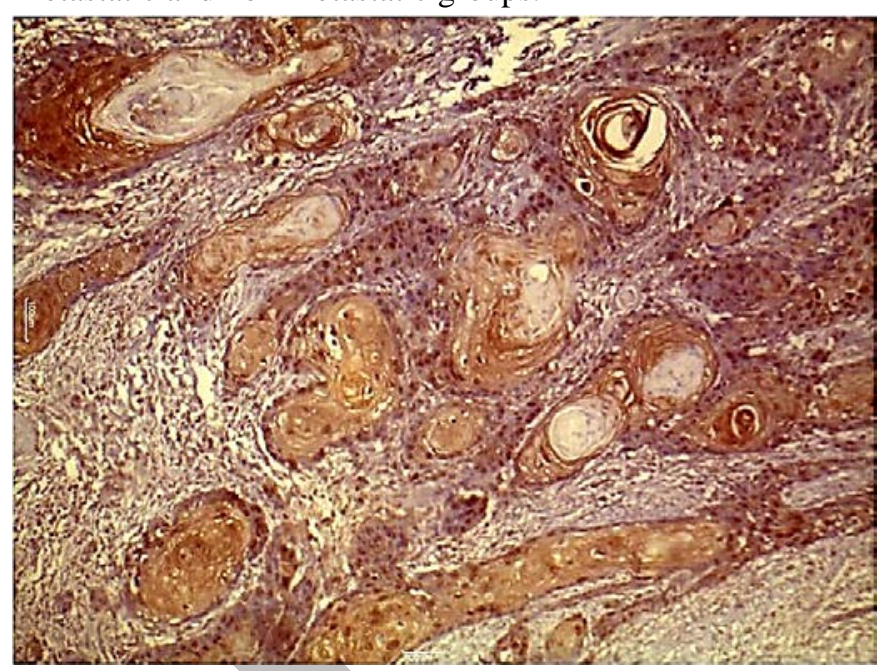

Figure 1: Well differentiated OSCC exhibiting a cytoplasmic immunoreaction of MTA1 (Immuno stain of MTA1 x 100).

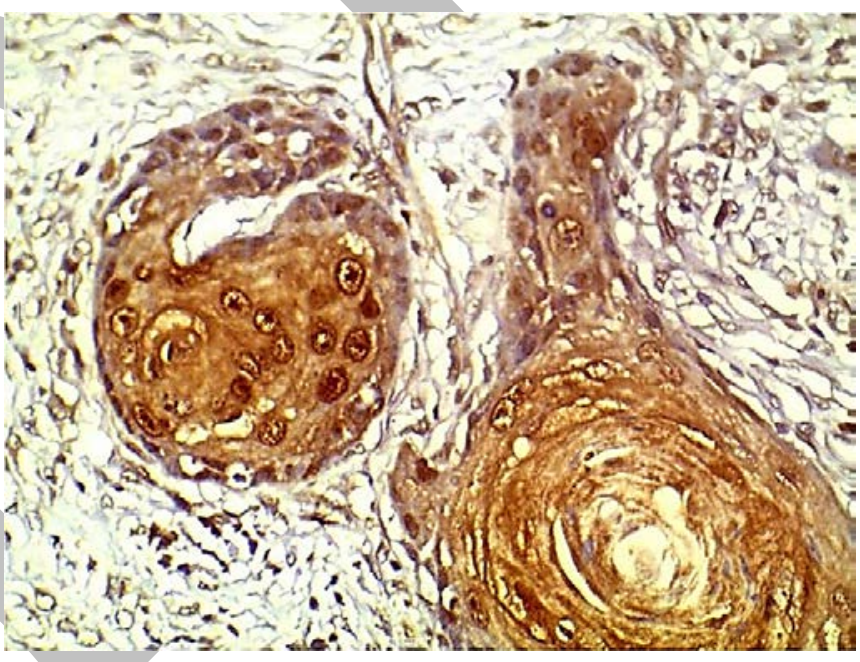

Figure 2: Moderately differentiated OSCC showing both nuclear and cytoplasmic reaction of MTA1 in the malignant cells forming the epithelial cell nest, as well as the epithelial pearl. (Immuno stain of MTA1 x 400).

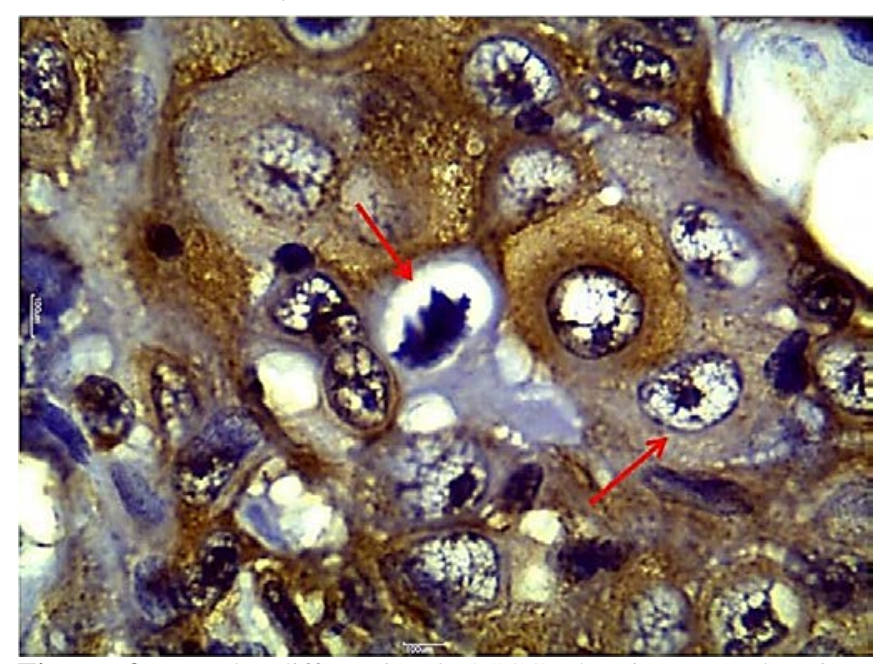

Figure 3: Poorly differentiated OSCC showing cytoplasmic immunopositive reaction of MTA1 in malignant epithelial cells. Note the vesicular nuclei and mitotic figures (arrow). (Immuno stain of MTA1 x 1000). 


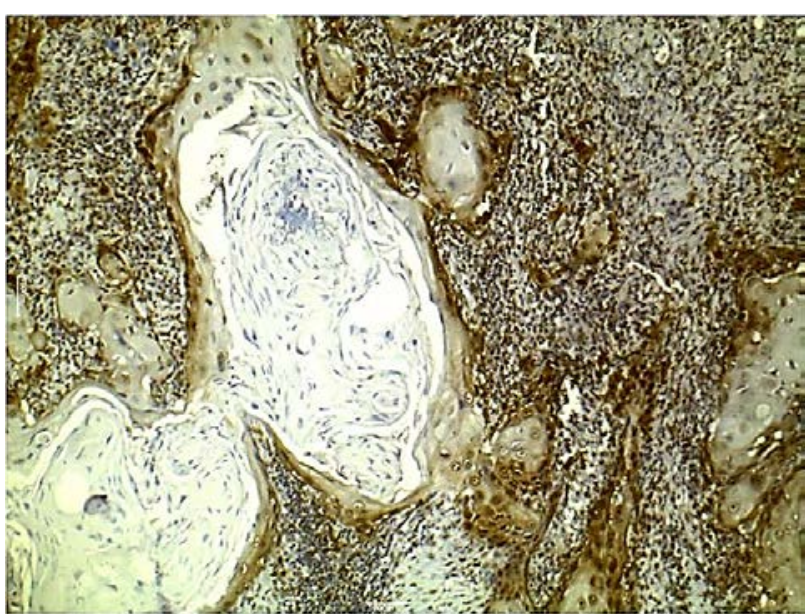

Figure 4: Well differentiated OSCC showing nuclear immunoreaction of PCNA in the peripheral malignant cells. The keratin is free from the reaction. (Immuno stain of PCNA x 100).

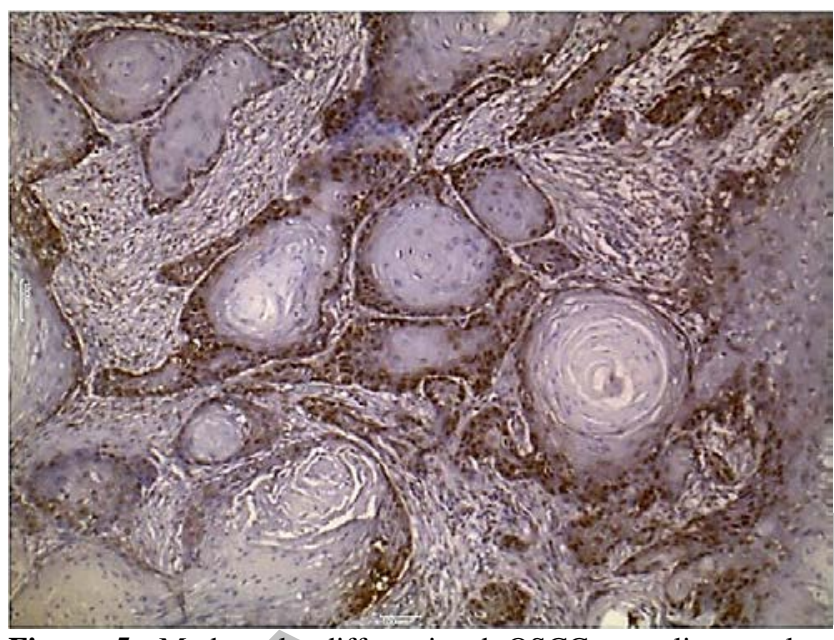

Figure 5: Moderately differentiated OSCC revealing nuclear immunoreaction of PCNA at the periphery of the cell nests. The central malignant epithelial cells are devoid of any reaction. (Immuno stain of PCNA x 100).

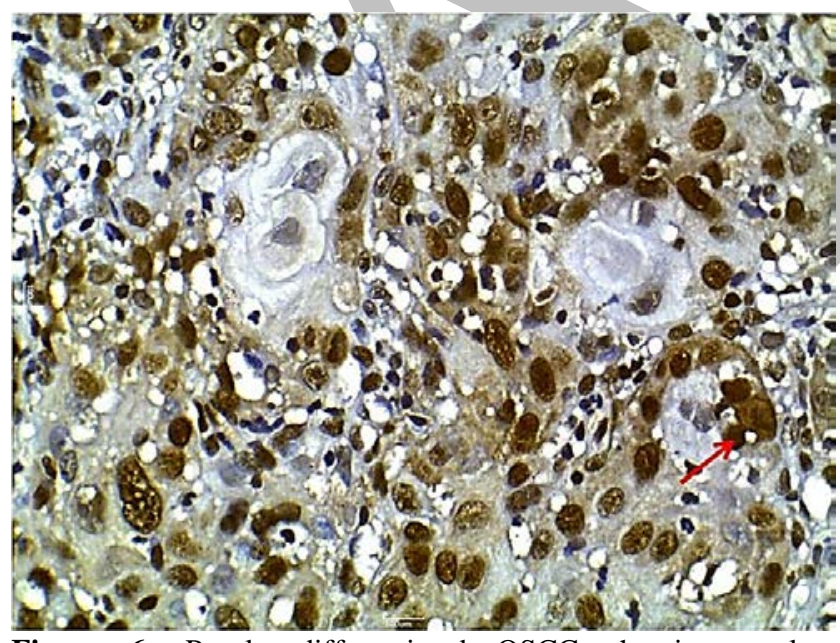

Figure 6: Poorly differentiated OSCC showing nuclear immunoreaction of PCNA in the malignant epithelial cells. Notice the mitosis (arrow). (Immuno stain of PCNA x 400)

\section{DISCUSSION}

The expression of MTA1 protein has been studied in several human tumors and was found to be closely correlated with tumor prognosis (9-11). The current study showed that the expression of MTA1 protein was significantly correlated with the lymph node metastasis in OSCC cases. This is in accordance with the findings of Roepman et al (12) who found MTA1 to be consistently correlated to tumor metastasis in head and neck SCC. In a study that included 38 OSCC patients, Kawasaki et al (13) also found that MTA1 expression is correlated to lymph node metastasis.

Controverting to these findings, in his study on 108 prostate cancer patients, Hofer et al (19) concluded that MTA1 expression was associated with a better outcome. They attributed this finding to other interrelated parameters, not examined in their study.

In the present study, cytoplasmic expression of MTA1 was predominant; although nuclear staining was also detected in the malignant epithelial cells. This is inconsistent with other studies of OSCC $(12,13)$, breast carcinoma (20), prostatic carcinoma (11) and gastric carcinoma (21) in which MTA1 predominantly localizes to the nucleus; owing to the presence of basic amino acid rich nuclear localization signals (22).

However, both cytoplasmic and nuclear expression of MTA1 was reported in human B-cell lymphomas (23), endometrial carcinomas (24), human hepatocelluar carcinomas (25) and colon cancer (26).

Liu et al (26) conducted a study to explain this complexity. They used multiple molecular technologies, and proposed that the nuclear and cytoplasmic components of MTA1 may drive cancer progression through different mechanisms. They provided the first evidence that MTA1 is localized to the nucleus, the cytoplasm and the nuclear envelope. In the study, they also revealed that MTA1 is localized to the microtubules in the cytoplasm; suggesting that since microtubules are important for cell mobility, they must be particularly higher in metastatic cancer cells. They also studied MTA1 expression in colon cancer, and revealed that cytoplasmic expression is significantly associated with tumor metastasis. These findings support the results of the current study.

Furthermore, Aramaki et al (27) demonstrated that MTA1 directly interacts with cytoplasmic protein endophilin 3; which might provide another explanation to the cytoplasmic localization observed in the current study.

Although both nuclear and cytoplasmic MTA1 are involved in promoting malignancies, the different subcellular locations and interacting partners may confer different functions, yet to be revealed (26).

A meta-analysis of cohort studies found no correlation between MTA1 expression and the degree of tumor differentiation (28). This is in accordance with the results observed in the current study; in which an insignificant correlation was found between the expression of MTA1 and tumor differentiation. Nevertheless, a study conducted on cervical cancer reported significant correlation with tumor differentiation in contrast to the present results (29).

Since cell proliferation is a requirement for tumor progression, much attention has been paid to the role of PCNA in tumors. In fact, PCNA was found to be involved in the prognosis of many cancers (16).

In the present study, PCNA showed no value as a prognostic marker. No significant correlation was detected between PCNA expression and nodal metastasis. This is in accordance with Kato et al (14) and Ahmed (30).

Opposing to the present results, Myoung et al (18) found a significant correlation between PCNA expression and lymph node metastasis in OSCC. In addition, a metaanalysis of non-small cell lung cancer (31), reported a 
positive correlation between PCNA expression and poor prognosis in terms of overall survival. Likely, another metaanalysis conducted on gastric cancer (16) indicated that PCNA may be a prognosticator of poor survival in gastric cancer patients.

In the current study, a significant correlation was detected between PCNA expression and the histologic grade of the tumor. This is consistent with several publications (32-36); owing to the proliferative function of PCNA and its roles in DNA replication and cell-cycle control. However, a study on laryngeal carcinoma (37) showed no correlation between PCNA expression and the degree of histologic differentiation.

PCNA immunoexpression was found to be predominantly nuclear in the current study; especially confined to the basal and suprabasal cells. This is in agreement with Madan et al (38), who found both intranuclear and faint intracytoplasmic staining. Likewise, Stabiano et al (39) and Al Azzawi (33) reported that immunostaining was restricted to the nuclei. However, Pena et al (32) reported positive immunostaining in nuclei and the cytoplasm of mitotic cells.

\section{CONCLUSIONS}

The present study suggests that MTA1 protein may have a clinical potential to be used as a prognostic factor to identify pathologically node-negative OSCC patients who may be at high risk to develop regional metastasis and hence a poor prognosis. It is proposed that MTA1 protein is a potential prognostic biomarker; thus an MTA1-positive status might be a reliable parameter for selection of elective neck dissection in the management of pathologically nodenegative (pN0) OSCC patients. In addition, the possibility of MTA1 protein being used as a therapeutic target should be considered.

This study shows that PCNA is unlikely to play an important role in predicting occult neck metastasis in pNO OSCC patients since it might not be directly involved with the metastatic behavior of individual cancer cells. Given these observations; it is concluded that PCNA is unsuitable as a biological marker predictive of lymph node metastases in OSCC.

\section{CONFLICT OF INTEREST}

The authors declare no conflict of interest.

\section{REFERENCES}

1. Yang YH, Sue RL, Warnakulasuriya S, Dasanayake AP. Promoting better oral health practices among aboriginal Taiwanese adolescents: a school based oral health education intervention program. J Health Care Poor Underserved. 2009; 20:41-50.

2. Shah JP, Candela FC, Poddar AK. The patterns of cervical lymph node metastases from squamous carcinoma of the oral cavity. Cancer. 1990; 66:109-13.

3. Beenken SW, Urist MM. Head and neck tumors. In: Way LW, Doherty GM, editors. Current surgical diagnosis and treatment. $11^{\text {th }}$ ed. New York: Lange Medical Books/McGraw-Hill; 2003: 282-97.

4. Ferlay J, Soerjomataram I, Dikshit R, Eser S, Mathers C, Rebelo M, et al. Cancer Incidence and mortality worldwide: sources, methods and major patterns in GLOBOCAN 2012. Int J Cancer. 2015;136: E359-86.
5. World Health Organization. The World Oral Health Report 2003. Geneva: WHO; 2003.

6. U.S. Department of Health and Human Services. Oral health in America: a report of the Surgeon Generalexecutive summary. Rockville (MD): US Department of Health and Human Services, National Institute of Dental and Craniofacial Research, National Institutes of Health; 2000. 1-13.

7. Leemans CR, Braakhuis BJ, Brakenhoff RH. The molecular biology of head and neck cancer. Nat Rev Cancer. 2011; 11:9-22.

8. Kumar R, Wang RA, Bagheri-Yarmand R. Emerging roles of MTA family members in human cancers. Semin Oncol. 2003; 30:30-7.

9. Li SH, Tian H, Yue WM, Li L, Gao C, Li WJ, et al. Metastasis-associated protein 1 nuclear expression is closely associated with tumor progression and angiogenesis in patients with esophageal squamous cell cancer. World J Surg. 2012; 36:623-31.

10. Lee SH, Chung YH, Kim JA, Lee D, Yin YJ, Shim JH, et al. Single nucleotide polymorphisms associated with metastatic tumour antigen 1 overexpression in patients with hepatocellular carcinoma. Liver Int. 2012; 32:457-66.

11. Dias SJ, Zhou X, Ivanovic M, Gailey MP, Dhar S, Zhang L, et al. Nuclear MTA1 overexpression is associated with aggressive prostate cancer, recurrence and metastasis in African Americans. Sci Rep. 2013; 3:2331.

12. Roepman P, de Jager A, Groot Koerkamp MJ, Kummer JA, Slootweg PJ, Holstege FC. Maintenance of head and neck tumor gene expression profiles upon lymph node metastasis. Cancer Res. 2006; 66:11110-14.

13. Kawasaki G, Yanamoto S, Yoshitomi I, Yamada S, Mizuno A. Overexpression of metastasis-associated MTA1 in oral squamous cell carcinomas: correlation with metastasis and invasion. Int J Oral Maxillofac Surg. 2008; 37:1039-46.

14. Kato K, Kawashiri S, Yoshizawa K, Kitahara H, Okamune A, Sugiura S, et al. Expression form of p53 and PCNA at the invasive front in oral squamous cell carcinoma: correlation with clinicopathological features and prognosis. J Oral Pathol Med. 2011; 40:693-8.

15. Diamandis EP, Christopoulos TK. The Biotin-(Strept) Avidin System: Principles and Applications in Biotechnology Clin Chem. 1991; 37:625-36.

16. Yin S, Li Z, Huang J, Zhang J, Lu C, Xu H, et al. Prognostic value and clinicopathological significance of proliferating cell nuclear antigen expression in gastric cancer: a systemic review and meta-analysis. Onco Targets Ther. 2017; 10:319-27.

17. Abdulkadir S, Ali NR, Alchalabi NJ. Pathological study of oral squamous cell carcinoma by application of p53 and PCNA (immunohistochemical approach). Int J Curr Microbiol App Sci. 2016; 5:91-100.

18. Myoung H, Jim MJ, Lee JH, Ok YJ, Paeng JY, Yun PY. Correlation of proliferative markers (ki-67 and PCNA) with survival and lymph node metastasis in oral squamous cell carcinoma: a clinical and histopathological analysis of 113 patients. Int J Oral Maxillofacial Surg. 2006; 35:1005-10.

19. Hofer MD, Kuefer R, Varambally S, Li H, Ma J, Shapiro GI, et al. The role of metastasis-associated protein 1 in prostate cancer progression. Cancer Res. 2004; 64:825-9.

20. Martin MD, Hilsenbeck SG, Mohsin SK, Hopp TA, Clark GM, Osborne CK, et al. Breast tumors that overexpress nuclear metastasis-associated 1 (MTA1) protein have high 
recurrence risks but enhanced responses to systemic therapies. Breast Cancer Res Treat. 2006; 95:7-12.

21. Deng X, Du L, Wang C, Yang Y, Li J, Liu H, et al. Close association of metastasis-associated protein 1 overexpression with increased angiogenesis and poor survival in patients with histologically node-negative gastric cancer. World J Surg. 2013; 37:792-8.

22. Kaur E, Gupta S, Dutt S. Clinical Implications of MTA proteins in human cancer. Cancer Met Rev. 2014; 33:101724.

23. Hofer MD, Tapia C, Browne TJ, Mirlacher M, Sauter G, Rubin MA. Comprehensive analysis of the expression of the metastasis-associated gene 1 in human neoplastic tissue. Arch Pathol Lab Med. 2006; 130:989-96.

24. Balasenthil S, Broaddus RR, Kumar R. Expression of metastasis-associated protein 1 (MTA1) in benign endometrium and endometrial adenocarcinomas. Human Pathol. 2006; 37:656-61.

25. Moon WS, Chang K, Tarnawski AS. Overexpression of metastatic tumor antigen 1 in hepatocellular carcinoma: relationship to vascular invasion and estrogen receptoralpha. Hum Pathol. 2004; 35:424-9.

26. Liu J, Xu D, WangH, Zhang Y, Chang Y, Zhang J, et al. The subcellular distribution and function of MTA1 in cancer differentiation. Oncotarget. 2014; 5:5153-64.

27. Aramaki Y, Ogawa K, Toh Y, Ito T, Akimitsu N, Hamamoto H, et al. Direct interaction between metastasisassociated protein 1 and endophillin 3. FEBS Letter, 2005;579:3731-6.

28. Luo H, Li H, Yao N, Hu L, He T. Metastasis-associated protein 1 as a new prognostic marker for solid tumors: a metanalysis of cohort studies. Tumour Biol. 2014; 35:582332.

29. Liu T, Yang M, Yang S, Ge T, Gu L, Lou G. Metastasisassociated protein 1 is a novel marker predicting survival and lymph nodes metastasis in cervical cancer. Hum Pathol. 2013; 44:2275-81.

30. Ahmed M. Expression profile of apoptotic mediators and proliferative markers in oral squamous cell carcinoma. J Egypt Natl Canc Inst. 2009; 21:85-92.

31. Fan J, Zhou X, Huang J, Wang X, Che G. Prognostic roles of PCNA expression in non-small cell lung cancer: a metaanalysis. Int J Clin Exp Med. 2016; 9:5655-65.

32. Pena L, Nieto A, Perez-Alenza D, Cuesta P, Castano M. Immunohistochemical detection of ki-67 and PCNA in canine mammary tumors: relationship to clinical and pathologic variables. J Vet Diagn Invest. 1998; 10:237-46.

33. Al Azzawi LM. Immunohistochemical analysis of PCNA and p53 proteins in oral lichen planus, oral dysplasia and normal oral mucosa. DJM. 2014; 6:41-7.

34. Tanai, M, Tomimatsu M, Okuda H, Saito A, Obata H. Immunohistochemical detection of proliferating cell nuclear antigen in hepatocellular carcinoma: relationship to histological grade. J Gastroenterol Hepatol. 1998; 8:420-5.

35. Adachi E, Hashimoto H, Tsuneyoshi M. Proliferating Cell Nuclear Antigen in Hepatocellular Carcinoma and small cell liver dysplasia. Cancer. 1993; 72:2902-9.

36. Kitamoto M, Nakanishi T, Kira S, Kawaguchi M, Nakashio $\mathrm{R}$, Suemori S, et al. The assessment of proliferating cell nuclear antigen immunohistochemical staining in small hepatocellular carcinoma and its relationship to histologic characteristics and prognosis. Cancer. 1993; 72:1859-65.
37. Micozkadioglu D, Unal M, Pata YS, Basturk M, Cinel L. Prognostic value of expression of p53, proliferating cell nuclear antigen and c-erb02 in laryngeal carcinoma. Med Sci Monit. 2008;14:CR299-304.

38. Madan M, Chandra S, Raj V, Madan R. Evaluation of cell proliferation in malignant and potentially malignant oral lesions. J Oral Maxillofac Pathol. 2015; 19:297-305.

39. Staibano S, Mignogna MD, Muzio LL, Alberti L, Natale E, Lucariello A, et al. Overexpression of cyclin-D1, bcl-2 and bax proteins, proliferationg cell nuclear antigen (PCNA), and DNA-ploidy in squamous cell carcinoma of the oral cavity. Hum Pathol. 1998; 29:1189-94.

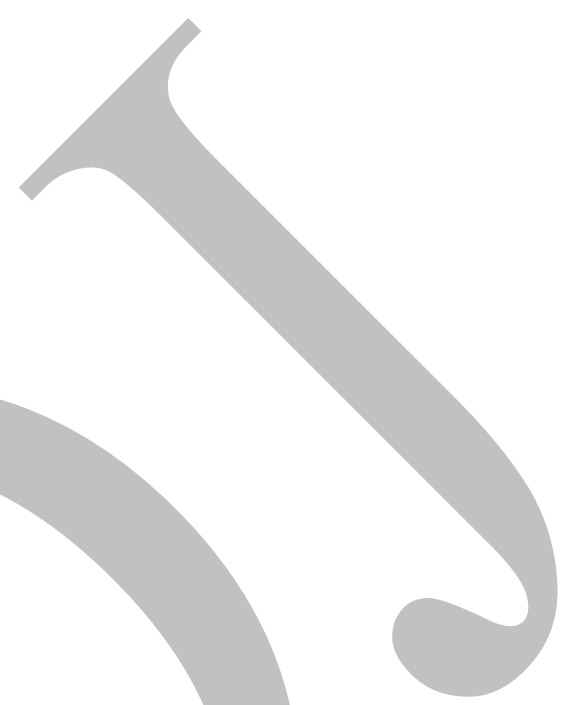

